\title{
The prevalence of gastroesophageal reflux and helicobacter pylori in chronic non-specific pharyngolaryngitis
}

\author{
Randa A Abdallah ${ }^{*}$, Gehan Shalaby ${ }^{1}$, Nashwa Y Elkhouly ${ }^{2}$, Fayka Karem ${ }^{3}$ and Abla Saab ${ }^{4}$ \\ ${ }^{1}$ Department of Otorhinolaryngology and Head and Neck Surgery, AL Azhar University Hospitals, Cairo, Egypt \\ ${ }^{2}$ Department of Internal Medicine, AL Azhar University Hospitals, Cairo, Egypt \\ ${ }^{3}$ Department of Radiology, AL Azhar University Hospitals, Cairo, Egypt \\ ${ }^{4}$ Department of Anesthesia and Intensive Care, Ain Shams University Hospitals, Cairo, Egypt
}

\begin{abstract}
Aim: to identify the association incidence of $H$. pylori infection and gastroesophageal reflux in the patients suffering from chronic non-specific pharyngolaryngeal diseases symptoms.

Material and methods: Urea breath test, gastrointestinal (GI) endoscopy, flexible pharyngolaryngeal endoscopies from 76 adult patients suffering from chronic nonspecific laryngeal and pharyngeal diseases symptoms

Result: Among 76 patients represented with chronic pharyngolaryngitis there were $(41 \pm 0.45)$ complaining of dysphagia $(54 \pm 0.45)$ of foreign body sensation $(46 \pm$ $0.5)$, of chronic dry cough $(39 \pm 0.5)$, with nocturnal choking $(67 \pm 0.48)$ with recurrent sore throat $(48 \pm 0.37)$, with post nasal drip, $(63 \pm 0.35)$ of frequent hawking $(41$ $\pm 0.48)$,voice fatigue $(49 \pm 0.5)$, of heart burn, $(51 \pm 0.47)$ with posterior laryngeal edema $(51 \pm 0.36)$, with vocal cord edema and erythema (12 \pm 0.5$)$ with vocal cord nodule, there were 42(55.2\%) GER , 41(53.9\%)with gastritis, with 21(27.6\%) gastric ulcers and 27(35.5\%) H. pylori positive patients and 7 (9.2\%) non- GER non-H. pylori with significant $\mathrm{p}$ value $(\mathrm{p}<0.05)$. No significant relationships between $H$. pylori infection and GER found in the chronic non-specific pharyngeolaryngitis and patients' demographic data, their unhealthy habits and reflux-related symptoms or signs were obtained.
\end{abstract}

Conclusion: There was a high prevalence association between both $H$. pylori infection and GER with chronic non-specific pharyngeolaryngitis, and the GER is significantly higher in its association with chronic non-specific pharyngolaryngitis.

\section{Introduction}

It has been well demonstrated that gastroesophageal reflux is a retrograde flow of gastric contents into the esophagus, leading to disorders in organs other than the esophagus [1]. In contrast to the typical presentation of classic GER with heartburn and distal esophageal acid regurgitation after transient relaxation of the lower esophageal sphincter, extraesophageal reflux disease, termed laryngopharyngeal reflux often results in atypical manifestations with pharyngeal, laryngeal, and pulmonary disorders [2]. GER was well known to be a contributing factor in posterior laryngitis and laryngeal contact ulceration or granuloma formation, laryngeal cancer, chronic hoarseness, pharyngitis, asthma, pneumonia, nocturnal choking [3]. GER diseases were believed to cause esophageal reflux of gastric contents with direct contact and subsequent injury of the pharyngeal or laryngeal mucosal surfaces [4].

Because many patients are not aware of GERD as a possible causative factor for their varying medical complaints, they may present to otolaryngologists with symptoms such as dry or sore throat, Globus sensation, hoarseness, chronic cough, dysphagia, or buccal burning [5]. However, otolaryngologic examinations merely demonstrate striking pathological findings, and the underlying disease of LPR is not primarily diagnosed. Frequently, the misdiagnosed patients are commonly treated for (non-allergic) rhinitis with postnasal drip, nonspecific rhino pharyngitis, or recurrent sinusitis [6]. Helicobacter pylori infection caused by a gram-positive curved or spiral organism was considered as one of the most common gastric human bacterial infections, affecting more than half of the world's population [7]. It had been proved that $H$. pylori played a significant role in the pathogenesis of chronic gastritis, duodenal and gastric ulcers, adeno carcinoma, and gastric lymphoma [8]. Although, the primary localization of this bacterium is the gastric mucosa, the recent literatures conducted that $H$. pylori might also be isolated from saliva, pharyngeal lymphoid tissue, nasal and sinus mucosa, oropharyngeal aphtha's ulcers, middle ear effusion, and larynx [9]. H. pylori could also cause vocal fold polyps, laryngeal cancer and other benign laryngeal lesions [10]. Some recent studies and had demonstrated that $H$. pylori could be an independent risk factor for the development of the hypopharyngeal carcinoma. Despite of the fact that modern scientists have been performing so many researchers on $H$. pylori, the routes of the bacteria entering the upper airway, as well as the relationship between gastroesophageal reflux and $H$. pylori in the upper airway also still unclear [10]

\section{Patients and methods}

The study was conducted at the ear, nose and throat (ENT) department Taiba hospital and GIT department Amiri hospital

*Correspondence to: Randa A Abdallah, Department of Otorhinolaryngology and Head and Neck Surgery, AL Azhar University Hospitals, Cairo, Egypt, Tel: 0096599912384; E-mail: randa.atwa@yahoo.com

Key words: GER, H. pylori, pharyngolaryngitis

Received: May 12, 2018; Accepted: May 25, 2018; Published: May 29, 2018 
ministry of health, Kuwait from 2014 September to 2016 June. In 76 adult patients from 21 to 69 years old, who had experienced symptoms of chronic non-specific pharyngolaryngitis symptoms for 3 months or longer (dysphagia, odynophagia, Sore throat, heart burn, chronic cough, hemming, hawking, hoarseness of voice, post nasal discharge and foreign body sensation). The patients included 32 men and 44 women with a mean age of $(46.9 \pm 1.5)$ years. All patients were initially evaluated by complete medical history and physical examination with clinical ENT examination. CT scan of the para nasal sinuses were performed for all patients, neck ultrasound was also performed to exclude any thyroid or other neck swellings.

Nasopharyngeal endoscopy and flexible fiberoptic endoscopic laryngopharyngescopy, complete assessment (function, shape, color, appearance) of the mucosa lining the vocal and ventricular folds, the laryngeal cartilages, the posterior commissure, the interarytenoid area, and hypo-pharyngeal regions.

Laryngeal changes were reported as, inflammation, oedema, ulceration, and nodules formation. Laryngeal changes with erythema of the posterior vocal folds and inter arytenoid area were coded as posterior laryngitis. Mucosal changes of posterior laryngitis were often accompanied by oedema of the vocal folds and inflammatory reactions of the interarytenoid area.

Nowadays, the 13C-urea breath test (UBT) is one of the gold standard and reliable non-invasive methods for the diagnosis of $H$. pylori infection. The examination is simple, innocuous when, easy to repeat, highly accurate, and requires a low number of precautions to obtain reliable results. It is particularly suitable for epidemiological studies in children and adults, in all clinical conditions where endoscopy is not strictly necessary, and to check the success of eradication regimens. The new and cheaper measuring equipment, the possibility of using a lower urea dose in capsules, and the patients had to be fasting for not less than 4 hours the take the capsule and then wait for 15 minutes and then blow, as well as shorter than usual sampling times, will certainly promote an increasingly broader application of this test [11].

Gastrointestinal evaluation was done by upper gastrointestinal (GI) endoscopy performed with (oesophago gastro duodenoscopy, and the Gastrointestinal physician was blinded for the laryngeal findings. Esophago gastro duodenoscopy is a well-established diagnostic test to evaluate mucosal injury and define the severity of esophagitis and gastritis. Informed consent was taken before doing the procedure, Propofol $100 \mathrm{mg}$ IV was given and xylocain spry also was applied. In the present study, $\mathrm{pH}$ monitoring was not performed because not all the patients agreed to undergo this procedure. Verbal consent was from each patient before starting the management.

Patients with positive $H$. pylori were received medical triple regimen with $20 \mathrm{mg}$ omeprazole twice daily for one month, Klacid $500 \mathrm{mg}$ twice daily, and Amoxil 500mg three times daily for at least 15 days. Patients with reflux disease or gastritis, or both, received (20-40 $\mathrm{mg}$ ) omeprazole daily for at least 4 weeks, depending on the severity of the mucosal finding according to Severity. All patients were advised to follow general anti reflux precautions including avoiding the spicy food, elevating the head of the bed and not eating for 2 or 3 hours before bedtime, stop smoking and start walking.

\section{Results}

\section{Statistical method}

The data were analyzed using IBM SPSS program (version 22). Data were expressed as (mean $\pm \mathrm{SD}$ ). The level of significance was taken as p-value $\leq 0.05$ and the results are presented in tables. Comparison of the study groups was done by Chi-square test $\left(\chi^{2}\right)$ and Macnemar test.

\section{The demographic line data}

The study contained 76 patients $32(42.1 \%)$ males and $44(57.9 \%)$ females as shown in Table 1. The age range was 44 to 66.3 years old with mean age $(46.9 \pm 1.5), 33(43.4)$ of them were smokers, 19 GER, $18 \mathrm{H}$. pylori positive and 1 non-GER non $H$. pylori. The patients presented with varying oral, pharyngeal, laryngeal, and pulmonary symptoms lasting for at least 3 months. There were 41 (53.9\%) patients (22 GER, $16 \mathrm{H}$. pylori and 3 non-GER non $H$. pylori positive) complaining of dysphagia, 54(71.1\%) (29 GER, $23 \mathrm{H}$. pylori and 2 non-GER non $H$. pylori) complaining of foreign sensation, 46(60.5\%)(20 GER $22 \mathrm{H}$. pylori and 4 non-GER non $H$. pylori) were represented with chronic dry cough sensation, 39(51.3\%) (22 GER,13 H. pylori and 4 non-GER non $H$. pylori) were complaining of chocking, 36(47.4\%) (20 GER, $13 \mathrm{H}$. pylori and 3 non-GER non $H$. pylori) were represented with hoarseness of voice, 67(88.2\%) (37 GER , $23 \mathrm{H}$. pylori and 7 non-GER non $H$. pylori) complaining of recurrent sore throat, 48(63.2\%) (26 GER, $17 \mathrm{H}$. pylori and 5 non-GER non $H$. pylori )were represented with chronic post nasal drip, 63(82.9\%) (35 GER,22 $H$. pylori and 6 non-GER non $H$. pylori) complaining of howking, 41(53.9\%) (23 GER,12 H. pylori and 6 non-GER non- $H$. pylori)with voice fatigue,49(64.5\%)of heart burn 29 patient in GOR,16 in $H$. pylori and 4 in non-GER non $H$. pylori. As shown in Table 2.

There was a significant difference with $\mathrm{p}$ value $<0.05$ in smoking, dry cough and foreign body sensation being more presented in GER patients than the $H$. pylori positive patients, while in the other symptoms there were no significant difference in their presentations.

\section{The result of Laryngopharyngeal endoscopies}

Inflammatory disorders and allergic rhinitis of the nose and the para nasal sinuses were excluded by history, nasal endoscopy, and Water's view $\mathrm{x}$-ray or computed tomography scan of the paranasal sinuses in all patients (Figure 1).

As shown in Table 3, There were 51(67.1\%) (27 GER, 18 H. pylori and 6 non-GER non- $H$. pylori) had posterior laryngeal oedema, 44(57.8\%)(24 GER,15 H. pylori and 5 non-GER non- $H$. pylori) had vocal cord oedema and erythema, 12(15.8\%) (6 GER, $4 \mathrm{H}$. pylori and 2 non-GER non $H$. pylori) were represented with vocal cord nodule, with a significant difference with $\mathrm{p}$ value $<0.05$ for) for the incidence of GER, $H$. pylori patients and non-GER, non- $H$. pylori patients among chronic pharyngolaryngitis patients using chi square test while there were no significant difference ( $p$ value $>0.05$ ) for Posterior laryngeal oedema, Vocal cord oedema and erythema or Vocal cord nodule, as show in Figure 2.

\section{The result of upper gastrointestical (GI) endoscopyand urea breath tests}

As shown in Table 3, there were 27(35.5\%) of total 76 patients H. pylori positive and $42(55.3 \%)$ patients of total 76 patients were

Table 1. Showing the demographic data of the patients. No significance difference regarding to the age, sex for the groups of patients ( $\mathrm{p}$ value $>0.05$ )

\begin{tabular}{|c|c|c|}
\hline Sex & Number (76) & P value \\
\hline Male & 32 & \multirow{2}{*}{0.94} \\
\hline Female & 44 & \\
\hline Age & $46.9 \pm 1.5$ & \\
\hline
\end{tabular}


Table 2. Showing the demographic data of the patients. There is a significant difference (p value $<0.005$ ) for smoking and foreign body sensation using chi square test comparing all groups, but there is no significant difference ( $\mathrm{p}$ value $>0.05$ ) for the other symptoms

\begin{tabular}{|c|c|c|c|}
\hline & Number of total (76) & Percentage (\%) & P value \\
\hline Dysphagia & 41 & & \\
\hline GER & 22 & $53.90 \%$ & \\
\hline H. Pylori & 16 & & 0.7 \\
\hline non- GER, non- $H$. Pylori & 3 & & \\
\hline smoking & 33 & $43.40 \%$ & \\
\hline GER & 23 & & 0.05 \\
\hline H. Pylori & 9 & & \\
\hline non- GER, non- H. Pylori & 1 & & \\
\hline Horsness of voice & 36 & & \\
\hline GER & 20 & $47.30 \%$ & \\
\hline H. Pylori & 13 & & 0.96 \\
\hline non- GER, non- H. Pylori & 3 & & \\
\hline Voice weakness & 41 & & \\
\hline GER & 23 & $53.90 \%$ & \\
\hline H. Pylori & 12 & & 0.14 \\
\hline non- GER, non- $H$. Pylori & 6 & & \\
\hline Dry coughing & 48 & & \\
\hline GER & 20 & $63.10 \%$ & \\
\hline H. Pylori & 22 & & 0.019 \\
\hline non- GER, non- $H$. Pylori & 4 & & \\
\hline Foreign body sensation & 54 & & \\
\hline GER - H. Pylori & 29 & $71 \%$ & \\
\hline Non- GER non- $H$. Pylori & 23 & & 0.012 \\
\hline Post nasal drip & 48 & & \\
\hline GER & 26 & $63.10 \%$ & \\
\hline $\begin{array}{l}\text { H. Pylori -Non GER, } \\
\text { non-H. Pylori }\end{array}$ & 17 & & 0.88 \\
\hline Hawking & 63 & & \\
\hline GER - H. Pylori & 35 & $82.80 \%$ & \\
\hline Non- GER non- $H$. Pylori & 22 & & 0.95 \\
\hline Recurrent sore throat & 67 & & \\
\hline GER - H. Pylori & 37 & $88.10 \%$ & \\
\hline non- GER, non- $H$. Pylori & 23 & & 0.55 \\
\hline Heart burn & 49 & & \\
\hline GER -H. Pylori & 29 & $64.40 \%$ & \\
\hline non- GER, non- & 16 & & 0.6 \\
\hline H. Pylori & 4 & & \\
\hline
\end{tabular}

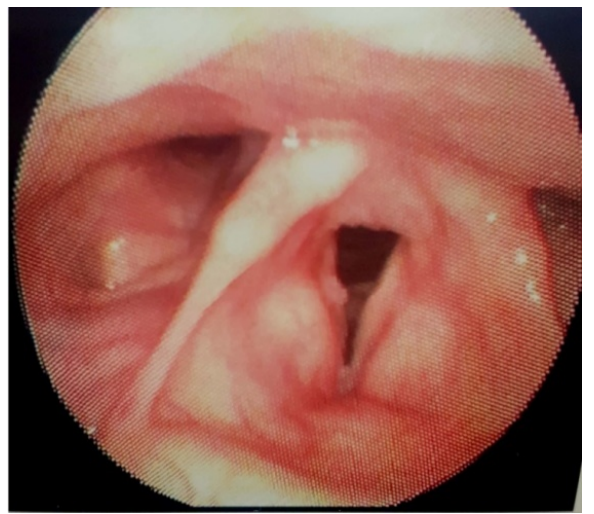

Figure 1. Right vocal cord minute nodule with posterior pharyngeal and vocal cords edema and congestion manifestation of GER

confirmed as GER disease positive and 7(9.7\%) patients had no H. pylori nor GER diseases showing a significant difference at $\mathrm{p}$ value $<0.005$ by using Macnemar test for the chronic non-specific pharyngolaryngitis. Also, there were 41(53.9\%) (14 GER, $H$. pylori and 0 non-GER non- $H$. pylori), had gastritis with a significant $\mathrm{p}$ value $<0.005$ (Figure 3 ).

\section{Discussion}

There is increasing evidence that GERD and hylicobacter pylori may be associated with chronic non-specific laryngopharyngeal diseases [12]. Sometimes, patients seem not to be aware about the extent of GERD or H. pylori and their associated extraesophageal laryngopharyngeal symptoms may be the early presentation. Apart of that fact is the patients with GERD often may become symptomatic in the upper respiratory tract, and laryngopharyngeal findings are subtle and sometimes hard to detect. The patient was mainly complaining of dysphagia, horsiness of voice and chronic dry cough for more 3 months, post nasal discharge, foreign body sensation, chocking, recurrent

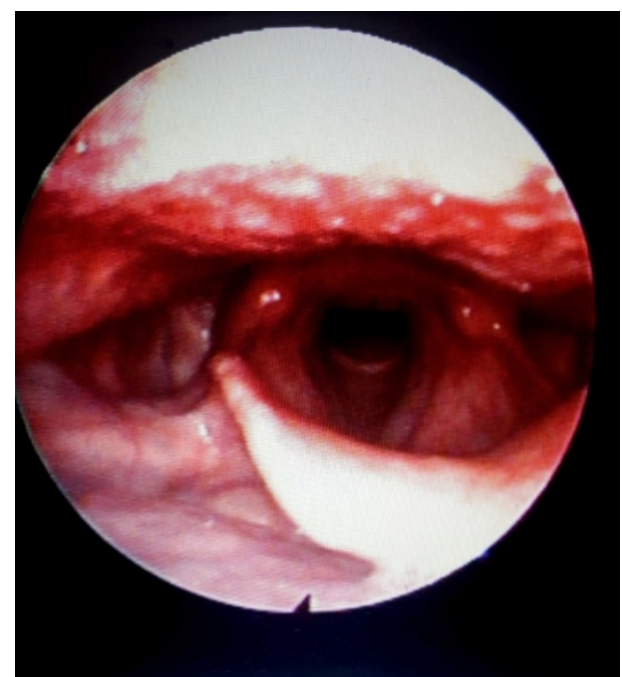

Figure 2. Inter arytenoids and vocal cords oedema and congestion

Table 3. There is a significant difference (p value $<0.005$ ) for the incidence of GER, $H$. Pylori patients and Non GER, Non H. Pylori patients among chronic pharyngolaryngitis patients, also for the incidence of gastritis among the groups of patients but there is no significant difference ( $\mathrm{p}$ value $>0.05$ ) for Posterior laryngeal edema, Vocal cord edema and erythema or Vocal cord nodule

\begin{tabular}{|c|c|c|c|}
\hline & No. & Name of test & P value \\
\hline GER patient & $42(55.3 \%)$ & \multirow{4}{*}{ Macnemar test } & \multirow{4}{*}{$\mathrm{P}<0.0001$} \\
\hline H. Pylori patients & $27(35.5 \%)$ & & \\
\hline $\begin{array}{l}\text { Non-GER, non- } H \text {. } \\
\text { Pylori patients }\end{array}$ & $7(9.2 \%)$ & & \\
\hline Gastritis & $41(53.9 \%)$ & & \\
\hline - GER - H. Pylori & 14 & \multirow[b]{2}{*}{ Macnemar test } & \multirow[b]{2}{*}{0.000} \\
\hline $\begin{array}{l}\text { - non- GER, non- } H \text {. } \\
\text { Pylori }\end{array}$ & 27 & & \\
\hline $\begin{array}{l}\text { Posterior laryngeal } \\
\text { oedema }\end{array}$ & $51(67.1 \%)$ & \multirow{4}{*}{ Macnemar test } & \multirow{4}{*}{0.53} \\
\hline - GER & 27 & & \\
\hline - H. Pylori & 18 & & \\
\hline $\begin{array}{l}\text { - non- GER, non- } H \text {. } \\
\text { Pylori }\end{array}$ & 6 & & \\
\hline $\begin{array}{l}\text { Vocal cord oedema } \\
\text { and erythema }\end{array}$ & $44(57.8 \%)$ & \multirow{5}{*}{ Macnemar test } & \multirow{5}{*}{0.57} \\
\hline - GER & 24 & & \\
\hline - H. Pylori & 15 & & \\
\hline - non- GOR, non- & 5 & & \\
\hline \multicolumn{2}{|l|}{ H. Pylori } & & \\
\hline Vocal cord nodule & $12(15.7)$ & \multirow{4}{*}{ Macnemar test } & \multirow{4}{*}{0.62} \\
\hline - GER - H. Pylori & 6 & & \\
\hline \multirow[t]{2}{*}{$\begin{array}{l}\text { - non- GER, non- } H \text {. } \\
\text { Pylori }\end{array}$} & 4 & & \\
\hline & 2 & & \\
\hline
\end{tabular}




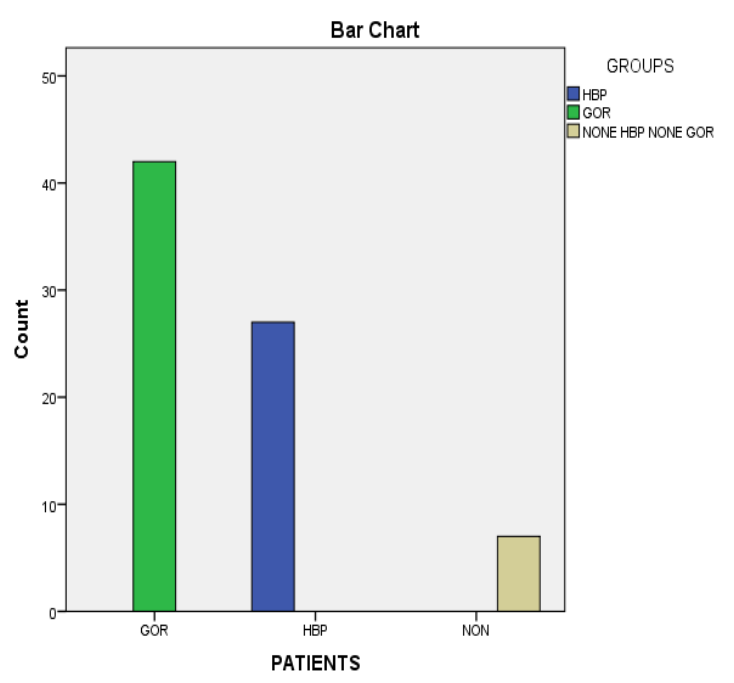

Figure 3. The prevalence of GER and H Pylori among the group of patients

sore throat, hawking, and heart burn those were the most common presentation of our patient group. Flexible pharyngolaryngoscopy showed posterior laryngeal oedema with erythema and oedema of the posterior part of the vocal cords, and minute vocal cord nodules and also it showed signs of chronic pharyngitis in all patients. The result of upper gastrointestinal (GI) endoscopy demonstrated GERD and some other upper gastrointestinal (GI) diseases. This result was also proved by Tauber et al, (13) who demonstrated that some of the laryngopharyngeal symptoms can be predictors of occult gastroesophageal diseases, including GERD or hiatal hernia. Symptoms such as dysphagia, sensation of Globus pharyngeus, postnasal drip, hoarseness, and other laryngeal disorders are not always caused by any primary otorhinolaryngological disease but may be related to upper GER diseases so a careful history, investigations and wide based knowledge of the disease syndromes are important for diagnosing GERD. In the present study, there were $53.9 \%$ of patients had different grads of gastritis being significantly higher in $\mathrm{H}$. pylori.

In the present study, there were about (55.2\%) of our chronic laryngopharyngitis had GER whereas, Deveney et al. [14] had demonstrated GERD by EGD in $43 \%$ of patients (13 of 28 ) with hypopharyngeal or laryngeal mucosal changes. other authors $[14,15]$ proved that more than (62\%) of their chronic pharyngolaryngitis patients had GER association, moreover from (30\% to 86\%) developed laryngopharyngeal reflux, as demonstrated by changes in the electrodes above the upper esophageal sphincter. Wilson et al. [16], conducted that at least $10 \%$ of all patients presenting to the ENT clinics have symptoms related to GERD4.

The wide ranges of GERD association incidence, which have been documented in all of those studies, might be explained by patient selection criteria, different laryngeal lesions, various definitions of "GER" disease, and also various methods of diagnosis GERD such as upper GIT endoscopy, 24-hour $\mathrm{pH}$ monitoring with single, double, or even triple probes, radiographic and manometric evaluation, and symptomatic assessment [17].

In the present study, there were (35.5\%) 27 of 76 patients represented with $H$. pylori positive diagnosed by urea breath test (Figure 3). Some literatures [18] conducted 23\% H. pylori positive in their study of total 30 patients. Tauber S et al. [13] showed that $H$. pylori infection in the biopsy material from the larynx was found in (45.5\%) of all the patients with chronic laryngitis and $(46.2 \%)$ in patients of laryngeal cancer. Burduk PK et al. [18] conducted that that $H$. pylori is identified in almost half of the investigated patients with benign laryngeal diseases (in 40.6\%-47.3\%) of cases. Izadi et al. [19] and Cekin et al. [20] had determined the association of $H$. pylori in $9.1-71.4 \%$ by using an accurate method of (PCR), while identifying $H$. pylori DNA which support the hypothesis of a possible relationship between the etiological $H$. pylori and benign laryngeal diseases. Zhuo et al. [21] demonstrated that the risk of developing laryngeal cancer is two times higher for the subjects infected with $H$. pylori, than for those in the control group, in their study using both serological studies data that show immune response to $H$. pylori, a marker of prior infection with this organism, and the research data of the biopsy material from the laryngeal region, $H$. pylori is found in $46-70 \%$ of cases of the patients with laryngeal cancer, i.e., significantly more often than in the patients operated for benign laryngeal lesions, which suggests that $H$. pylori may be an independent factor of squamous cell carcinoma of the larynx

H. pylori is a (microaerophilic), gram-negative spiral organisms. $H$. pylori has been proved to be associated with Several factors causing epithelial damage including vacuolizing cytotoxin (VacA), cytotoxin associated gene A (cagA), surface lipopolysaccharide (LPS), bacterial urease, flagella, surface adhesins, oxidizing radicals and cytokines produced by leukocytes. H. Pylori had lipopolysaccharide in its cell wall, which was considered as a powerful immunologic agent, stimulating an inflammatory reaction leading to endothelial cells destruction. $H$. pylori need a microaerophylic environment and $\left(5 \%\right.$ of $\left.\mathrm{CO}_{2}\right)$ is necessary for its reproduction. The produce urease enzyme which can alter the acidic environment to facilitate its colonization [22]. Although, the gastric mucosa was considered as the only habitat for $H$. pylori, it also was isolated from dental plaque, oral lesions, saliva, tonsils and adenoid tissue but the exact mechanism was still unclear. It was suggested that $H$. pylori contaminated gastric fluid enters to nasopharyngeal cavity by the GER and colonizes the pharyngeal and laryngeal mucosa. From these localizations, the bacterium ascends to the middle ear and the paranasal sinuses directly or by the reflux, and may trigger some pathological changes. Some literatures indicated that after nasopharyngeal mucosa exposure to gastric acid, Eustachian tube dysfunction developed also reflux of acidic gastric content to the nasopharynx and nose leads to oedema and congestion of nasopharyngeal mucosa, causing a disturbance of middle ear and paranasal sinus pressure regulation and clearance. This process predisposes the inflammation of upper respiratory system diseases [23]. The present study revealed a nonsignificant difference between the GER disease and $H$. pylori infection in relation to the age or the sex of the patients.

\section{Conclusion}

There was a high prevalence association between both $H$. pylori infection and GER with chronic non-specific pharyngeolaryngitis, and the GER is significantly higher in its association with chronic nonspecific pharyngolaryngitis.

\section{Compliance with ethical standards}

Conflicts of interest: All authors have read and approved the manuscript and have no conflict of interest related to this paper.

Informed consent: Informed consent was obtained from all parents of individual participants included in the study.

\section{Acknowledgments}

The authors thank the ENT and GIT departments and the all staff working in Tiaba hospital, Kuwait City, for their skillful assistance and help. 


\section{Summary}

- This study conducted the prevalence of GER and H. pylori infection in chronic pharyngolaryngitis patients.

- There was a significant higher association between GER and chronic pharyngolaryngitis.

- Sometimes patient is complaining of chronic cough or chocking for more than 3 monthes and he doesn't know that he has GER or $H$. pylori so ENT doctor has to investigate for them

- By good treatment for GER and H. pylori all the extra gastric symptoms will be improves.

\section{References}

1. Paterson WG (1997) Extraesophageal complications of gastroesophageal reflux disease. Can J Gastroenterol 11: 45B-50B. [Crossref]

2. Koufman JA, Armin MR, Panetti M (2000) Prevalence of reflux in 113 consecutive patients with laryngeal and voice disorders. Otolaryngol Head Neck Surg 123: 385388. [Crossref]

3. Wong RK, Hanson DG, Waring PJ, Shaw G (2000) ENT manifestations of gastroesophageal reflux. Am J Gastroenterol 95: S15-S22. [Crossref]

4. Koufman JA, Amin MR, Panetti M (2000) Prevalence of reflux in 113 consecutive patients with laryngeal and voice disorders. Otolaryngol Head Neck Surg 123: 385388. [Crossref]

5. Wong RK, Hanson DG, Waring PJ, Shaw G (2000) ENT manifestations of gastroesophageal reflux. Am J Gastroenterol 95: S15-S22. [Crossref]

6. Toohill RJ, Kuhn JC (1997) Role of refluxed acid in pathogenesis of laryngeal disorders. Am J Med 103: 100S-106S. [Crossref]

7. Gong H, Shi Y, Zhou L, Tao L, Shi Y, et al. (2012) Helicobacter pylori infection of the larynx may be an emerging risk factor for laryngeal squamous cell carcinoma. Clin Transl Oncol 14: 905-910. [Crossref]

8. Malfertheiner P, Megraud F, O'Morain CA, Gisbert JP, Kuipers EJ, et al. (2012) Management of Helicobacter pyloriinfection-the Maastricht IV/florence consensus report. Gut 61: 646-664.

9. Kusano K, Inokuchi A, Fujimoto K, Miyamoto H, Tokunaga O, et al. (2010) Coccoid Helicobacter pylori exists in the palatine tonsils of patients with IgA nephropathy. $J$ Gastroenterol 45: 406-412. [Crossref]
10. Gong H, Shi Y, Zhou L, Tao L, Shi Y, et al. (2012) Helicobacter pylori infection of the larynx may be an emerging risk factor for laryngeal squamous cell carcinoma. Clin Transl Oncol 14: 905-910. [Crossref]

11. Savarino V, Vigneri S, Celle G (1999) The 13C urea breath test in the diagnosis of Helicobacter pylori infection. Gut 45: I18-I22. [Crossref]

12. Koufman JA, Amin MR, Panetti M (2000) Prevalence of reflux in 113 consecutive patients with laryngeal and voice disorders. Otolaryngol Head Neck Surg 123: 385388. [Crossref]

13. Tauber S, Gross M, Issing WJ (2002) Association of laryngopharyngeal symptoms with gastroesophageal reflux disease. Laryngoscope 112: 879-886.

14. Deveney CW, Benner K, Cohen J (1993) Gastroesophageal reflux and laryngeal disease. Arch Surg 128: 1021-1025. [Crossref]

15. Shaker R, Milbrath M, Ren J, Toohill R, Hogan WJ, et al. (1995) Esophagopharyngeal distribution of refluxed gastric acid in patients with reflux laryngitis. Gastroenterology 109: 1575-1582. [Crossref]

16. Wilson JA, White A, von Haacke NP, Maran AG, Heading RC, et al. (1989) Gastroesophageal reflux and posterior laryngitis. Ann Otol Rhinol Laryngol 98: 405410. [Crossref]

17. Siupsinskiene N, Jurgutaviciute V, Katutiene I, Janciauskas D, Vaitkus S, et al. (2013) Helicobacter pylori infection Upper airway Benign laryngeal diseases Laryngeal cancer. Eur Arch Otorhinolaryngol 270: 2283-2288. [Crossref]

18. Burduk PK (2006) The role of helicobacter pylori infection in carcinoma of the larynx Otolaryngol Pol 60: 521-523. [Crossref]

19. Izadi F, Ahmadi A, Ghourchian S, Daneshi A, Memari F, et al. (2012) Detection of helicobacter pylori in benign laryngeal lesions by polymerase chain reaction: a cross sectional study. Infect Agent Cancer 7: 10. [Crossref]

20. Cekin E, Ozyurt M, Erkul E, Ergunay K, Cincik H, et al (2012) The association between Helicobacter pylori and laryngopharyngeal reflux in laryngeal pathologies. Ear Nose Throat J 91: E6-E9. [Crossref]

21. Zhuo XL, Wang Y, Zhuo WL, Zhang XY (2008) Possible association of Helicobacter pyloriinfection with laryngeal cancer risk: an evidence-based meta-analysis. Arch Med Res 39: 625-628. [Crossref]

22. Olivares D, Gisbert JP (2006) Factors involved in the pathogenesis of Helicobacter pylori infection. Rev Esp Enferm Dig 98: 374-386. [Crossref]

23. White DR, Heavner SB, Hardy SM, Prazma J (2002) Gastroesophageal reflux and eustachian tube dysfunction in an animal model. Laryngoscope 112: 955-961. [Crossref]

Copyright: $@ 2018$ Abdallah RA. This is an open-access article distributed under the terms of the Creative Commons Attribution License, which permits unrestricted use, distribution, and reproduction in any medium, provided the original author and source are credited. 